\title{
The Prevalence of Vitamin D Deficiency and Associated Risk Factors among General Populations in Duhok Province, Kurdistan Region, Iraq
}

\author{
Lina Y. Mohammed, Shaker A. Jamal, Nawfal R. Hussein, Ibrahim A. Naqid*
}

Department of Biomedical Sciences, College of Medicine, University of Zakho, Zakho Kurdistan Region, Iraq.

*Correspondence to: Ibrahim A Naqid (E-mail: ibrahim.naqid@uoz.edu.krd)

(Submitted: 10 September 2021 - Revised version received: 06 October 2021 - Accepted: 19 October 2021 - Published online: 26 December 2021)

\begin{abstract}
Objectives: This study aimed to determine the serum levels of 25(OH)D3 and associated risk factors in Duhok province, Kurdistan Region, Iraq.

Methods: A cross-sectional study was performed from January 2019 to September 2019 among the general population in Dohuk and Zakho cities. 1143 of subjects were recruited in this study and aged ranged from 9 months to 86 years old (36.31 \pm 17.61$)$. Serum 25(OH) D3 levels were measured using an enzyme-linked immunosorbent assay (ELISA) method.

Results: Of 1143 subjects, 229 (44.9\%) people were suffered from vitamin D deficiency in Duhok city and 241(38.19\%) from Zakho city. There was significant difference between the incidence of vitamin $D$ in both cities $(P<0.067)$. The prevalence of vitamin $D$ deficiency was $152(37.8 \%)$ in male and 318 (43.03\%) in females. There was no significantly associated with low level of vitamin $D$ between genders $(P<0.133)$. The low level of Vitamin D was more frequently found in age group between $20-40$ years old $(46.23 \%)$, with sufficient differences between age group $(P<0.001)$.

Conclusion: The prevalence of vitamin D deficiency is much predominant in Duhok province, younger adults and female population. Our finding also found that the low level of vitamin D deficiency in older people. Further studies are required to investigate the pathophysiology of hypovitaminosis $D$ and its clinical consequences.

Keywords: Vitamin D deficiency, general population, Duhok province, Kurdistan, Iraq
\end{abstract}

\section{Introduction}

Vitamin D, a lipid-soluble prohormone, plays a key role in human health by promoting the absorption and metabolism of calcium and phosphate $\mathrm{e}^{1,2}$ especially in bone formation and skeletal development. Vitamin D deficiency is associated with a wide variety of other health conditions, including cardiovascular disease, ${ }^{3}$ type 1 and 2 diabetes, ${ }^{4}$ chronic kidney disease, rheumatoid arthritis, ${ }^{5}$ increased risk of cancer, as well as cognitive dysfunction, schizophrenia and depression, ${ }^{6}$ rickets in children and osteomalacia in adults. ${ }^{7}$ Vitamin D may also be implicated in the risk of miscarriage due to its function as an immune modulator ${ }^{8}$ and its potential importance for the maternal-fetal immunologic response. ${ }^{9}$ Several studies have been conducted in Iraq about the potential causes of miscarriage among pregnant women, but have not reported the impact of Vit. D on pregnancy. ${ }^{10-12}$

The most studied types among five forms of vitamin $\mathrm{D}$ (D1 to D5) are vitamin D2 and D3 Vitamin. ${ }^{13}$ D2, ergocalciferol is synthesized in plants and invertebrates and is consumed in the human's diet and as supplements while D3 (cholecalciferol) comes from vertebrate animals such as fatty fish and meat, eggs. The major source of vitamin $\mathrm{D}$ is formed in the skin after exposure of 7-dehydrocholesterol to ultraviolet sun rays (vitamin D3) while minor source of vitamin D comes from food (vitamin D3, cholecalciferol) and from dietary supplements (vitamin D2, ergocalciferol) for synthesize a significant amount of vitamin D requirements. ${ }^{14}$ Vitamin D (D2 and D3) from the skin and diet are transported and metabolized in the liver to produce $25(\mathrm{OH})$ vitamin D3 which is used to determine the level of vitamin $\mathrm{D}$ in patients, then the kidney converted it by 25 -hydroxyvitamin $\mathrm{D}$ - 1 - - hydroxylase enzyme to its to its active form $1,25(\mathrm{OH}) 2$ vitamin $\mathrm{D}$. $^{15}$

In Iraq including Kurdistan Region, with sunlight throughout the year, vitamin D serum levels are expected to be adequate, yet studies from different Arab countries showed high prevalence levels of vitamin $\mathrm{D}$ deficiency and insufficiency. ${ }^{16,17}$ The prevalence of vitamin D deficiency level is very high and varies from $70 \%$ to $90 \%$ in different populations, globally. ${ }^{18}$

There is limited data on the prevalence of Vitamin D deficiency among the general population in Kurdistan RegionIraq. Determination of vitamin D status in different age-groups and gender in a community and in different climates of a country is necessary and has important implications for general public health. Therefore, the main objective of this study was to determine the levels of vitamin D 25(OH) among Zakho and Dohuk populations and determine associated risk factors as age and gender.

\section{Materials and Methods}

\section{Study Design and Sampling}

A cross sectional study was conducted in Azadi and Bedari hospitals in Dohuk and Zakho cities, Kurdistan region, Iraq. The study was conducted over a period of nine months from January 2019 to September 2019. A total of 1143 serum samples were collected (632 patients from Bedari hospital, Zakho city and 511 patients from Azadi hospital, Dohuk city). The ages of participants ranged from 9 months to 86 years old $(36.31 \pm 17.61)$.

An overnight fasting blood sample $(5 \mathrm{ml})$ was obtained for each patient by venepuncture. Serum 25(OH)D3 levels were measured within 24 hrs of blood collection in the hospital clinical laboratory using an enzyme-linked immunosorbent assay (ELISA) method supplied by (Bioactivia diagnostic $\mathrm{GmbH}$ ). The patients were classified into three diagnostic groups 
according to their serum concentrations of $25(\mathrm{OH}) \mathrm{D} 3$ by increasing the order of severity as follows: vitamin $\mathrm{D}$ deficiency, $15 \mathrm{ng} / \mathrm{mL}$ or less, vitamin D deficiency, (16-30 ng/mL); and vitamin D deficiency greater than $30 \mathrm{ng} / \mathrm{mL}$.

\section{Ethical Approval}

The study proposal was approved by the ethics committee of the College of the Medicine/University of Zakho, Kurdistan Region, Iraq. Informed written consent was obtained from all the participants before samples collection.

\section{Statistical Analysis}

The result of this study was analysed using the GraphPad Prism software package, version 8 . The results were expressed as the mean \pm standard deviation or as simple percentages as appropriate. Comparisons were made using the Chi-Square and Fisher Exact Test. The results were considered significant if $P \leq 0.05$.

\section{Results}

A total of 1141 participants were recruited in this study. Table 1 summarises the demographic characteristics of the total population. Of 1143 individuals, $402(35.23 \%)$ were male and $739(65 \%)$ of them were female. $510(45 \%)$ of participants were from Dohuk residency and 63 (55\%) from Zakho

\begin{tabular}{|c|c|c|c|}
\hline Variables & & Frequency & Percentage \\
\hline \multirow[t]{2}{*}{ Gender } & Male & 402 & $35.23 \%$ \\
\hline & Female & 739 & $65 \%$ \\
\hline \multirow[t]{2}{*}{ Residence } & Duhok & 510 & $45 \%$ \\
\hline & Zakho & 631 & $55 \%$ \\
\hline \multirow[t]{4}{*}{ Age group (Year) } & $<20$ & 188 & $16 \%$ \\
\hline & $20-40$ & 491 & $43 \%$ \\
\hline & $40-60$ & 332 & $29 \%$ \\
\hline & $>60$ & 130 & $11 \%$ \\
\hline
\end{tabular}

residency. The majority of participants 491 (43\%) were from $20-40$ years old, followed by $40-60$ years $332(29 \%)$, less than 20 years $188(16 \%)$ and greater than 60 years $130(11 \%)$. The mean age was $36.31 \pm 17.61$ years (ranged from 9 months to 86 years old).

According to the patient's serum $25 \mathrm{OHD}$ concentrations, three diagnostic categories were found in both Dohuk's and Zakho's population (Table 2). The incidence of vitamin D deficiency among Dohuk population was 229 (44.9\%) with mean value $(8.26 \pm 3.63)$. On the other hand, $241(38.19 \%)$ of Zakho study group were vitamin $\mathrm{D}$ deficient with mean value $(9.68 \pm$ 2.99). There was significant difference between the status of vitamin $\mathrm{D}$ level and their current residency when analysed using the Fisher Exact Test $(P=0.067)$.

The prevalence of Vitamin D deficiency levels in serum among gender in studied population are presented in Table 3. It was found that the prevalence of this nutritional deficiency in male was $152(37.8 \%)$ with the mean concentration $(8.97 \pm$ 3.51), 165 (41\%) were vitamin D insufficient with the mean concentration $(21.23 \pm 4.19)$ while only $85(21.1 \%)$ of participants were vitamin D sufficient. Analysis of vitamin D levels regarding female participants revealed that 318 (43.03\%) of them were deficient with the mean concentration $(9.03 \pm 3.33)$ while 261 (35.31\%) of female were vitamin D insufficient with the mean level concentration $(22.43 \pm 4.42) .160(21.65 \%)$ of female cases had vitamin $\mathrm{D}$ sufficient with the mean concentration (44.18 \pm 16.62). Using Fisher Exact Test, the differences between genders were statistically not significant $(P=0.133)$.

Associations between 25(OH)D level and age groups were also investigated (Table 4). Majority of them were between 20-40 years, 227 (46.23\%) of them were vitamin D deficient with the mean level $(9.12 \pm 3.42)$. The next age group were 40-60 years, 121 (36.44\%) of them were vitamin D deficient with the mean level $(8.74 \pm 3.37)$. The age group less than 20 years came in third order regarding to vitamin $\mathrm{D}$ levels, accounting for $83(44.14 \%)$ were vitamin D deficient with the mean level $(9.11 \pm 3.32)$. Of all participants in this study, least were in greater than 60 years age group accounting for 39 (30\%) of them were vitamin D deficient with the mean level $(8.78 \pm 3.48)$. Our results showed that there was a significant

\begin{tabular}{|c|c|c|c|c|c|}
\hline Variable & & $\begin{array}{c}\text { Deficient Number (\%) } \\
\text { Mean } \pm \text { SD }\end{array}$ & $\begin{array}{c}\text { Insufficient Number (\%) } \\
\text { Mean } \pm \text { SD }\end{array}$ & $\begin{array}{c}\text { Sufficient Number (\%) } \\
\text { Mean } \pm \text { SD }\end{array}$ & ${ }^{*} \boldsymbol{P}$ value \\
\hline \multirow[t]{2}{*}{ Residence } & Duhok & $\begin{array}{l}229(44.9 \%) \\
(8.26 \pm 3.63)\end{array}$ & $\begin{array}{l}177(34.70 \%) \\
(21.54 \pm 4.27)\end{array}$ & $\begin{array}{c}103(20.19 \%) \\
(45.85 \pm 18.27)\end{array}$ & 0.067 \\
\hline & Zakho & $\begin{array}{l}241(38.19 \%) \\
(9.68 \pm 2.99)\end{array}$ & $\begin{array}{l}249(39.46 \%) \\
(21.31 \pm 4.38)\end{array}$ & $\begin{array}{c}141(22.34 \%) \\
(44.19 \pm 19.06)\end{array}$ & \\
\hline
\end{tabular}

SD, Standard deviation. *P value was determined by Chi-Square (Fisher Exact Test).

\begin{tabular}{|c|c|c|c|c|c|}
\hline Variable & & $\begin{array}{l}\text { Deficient Number (\%) } \\
\quad * \text { Mean } \pm \text { SD }\end{array}$ & $\begin{array}{c}\text { Insufficient Number (\%) } \\
{ }^{*} \text { Mean } \pm \text { SD }\end{array}$ & $\begin{array}{l}\text { Sufficient Number (\%) } \\
\quad{ }^{*} \text { Mean } \pm \text { SD }\end{array}$ & $P$ value \\
\hline \multirow[t]{2}{*}{ Gender } & Male & $\begin{array}{l}152(37.8 \%) \\
(8.97 \pm 3.51)\end{array}$ & $\begin{array}{c}165(41 \%) \\
(21.23 \pm 4.19)\end{array}$ & $\begin{array}{c}85(21.1 \%) \\
(47.61 \pm 21.9)\end{array}$ & 0.133 \\
\hline & Female & $\begin{array}{l}318(43.03 \%) \\
(9.03 \pm 3.33)\end{array}$ & $\begin{array}{l}261(35.31 \%) \\
(22.43 \pm 4.42)\end{array}$ & $\begin{array}{c}160(21.65 \%) \\
(44.18 \pm 16.62)\end{array}$ & \\
\hline
\end{tabular}


Table 4. Comparison of serum level of vitamin $\mathbf{D}$ in nanogram/dl according to age group

\begin{tabular}{|c|c|c|c|c|c|}
\hline Variable & & $\begin{array}{l}\text { Deficient Number (\%) } \\
{ }^{*} \text { Mean } \pm \text { SD }\end{array}$ & $\begin{array}{c}\text { Insufficient Number (\%) } \\
{ }^{*} \text { Mean } \pm \text { SD }\end{array}$ & $\begin{array}{l}\text { Sufficient Number (\%) } \\
\quad * \text { Mean } \pm \text { SD }\end{array}$ & $P$ value \\
\hline \multirow[t]{4}{*}{ Age group (Year) } & $<20$ & $\begin{array}{l}83(44.14 \%) \\
(9.11 \pm 3.32)\end{array}$ & $\begin{array}{c}70(37.23 \%) \\
(21.11 \pm 4.22)\end{array}$ & $\begin{array}{c}35(18.61 \%) \\
(43.73 \pm 17.82)\end{array}$ & 0.001 \\
\hline & $20-40$ & $\begin{array}{l}227(46.23 \%) \\
(9.12 \pm 3.42)\end{array}$ & $\begin{array}{l}162(32.99 \%) \\
(21.17 \pm 4.19)\end{array}$ & $\begin{array}{c}102(20.77 \%) \\
(48.98 \pm 20.19)\end{array}$ & \\
\hline & $41-60$ & $\begin{array}{l}121(36.44 \%) \\
(8.74 \pm 3.37)\end{array}$ & $\begin{array}{l}145(43.67 \%) \\
(21.71 \pm 4.52)\end{array}$ & $\begin{array}{c}66(19.87 \%) \\
(40.65 \pm 19.51)\end{array}$ & \\
\hline & $>60$ & $\begin{array}{c}39(30 \%) \\
(8.78 \pm 3.48)\end{array}$ & $\begin{array}{c}49(37.69 \%) \\
(21.72 \pm 4.41)\end{array}$ & $\begin{array}{c}42(32.30 \%) \\
(42.60 \pm 11.65)\end{array}$ & \\
\hline
\end{tabular}

difference in serum $25(\mathrm{OH}) \mathrm{D}$ level between age subgroups $(P<0.001)$, indicating that the age can be considered as a risk factor of vitamin $\mathrm{D}$ deficiency.

\section{Discussion}

The roles vitamin $\mathrm{D}$ have found in many physiological functions. It facilitates the absorption of calcium and phosphorus, which is important to prevent osteoporosis or fragility fractures development. Vitamin D deficiency and insufficiency is a worldwide common health issue and nowadays is linked with many diseases therefore measuring circulating levels of 25 OHD provides evidence of a person's deficiency/insufficiency of vitamin D. ${ }^{1}$ Therefore, the purpose of this study was to evaluate the prevalence of vitamin D deficiency and insufficiency among Dohuk and Zakho population and further to investigate whether age and sex variations in serum $25 \mathrm{OHD}$ are evident among these population in Kurdistan Region, Iraq.

In the present study, the status of vitamin D is measured in 1141 blood samples of both genders. It was observed in our population that vitamin $\mathrm{D}$ was deficient in $41.19 \%$ population while the $37.33 \%$ had insufficient vitamin D levels. Furthermore, vitamin D deficiency was found in $43.03 \%$ of females while $35.31 \%$ of females were having insufficient vitamin $\mathrm{D}$ levels. This showed that females are more deficient to vitamin $\mathrm{D}$ than males. However, there is no statistical difference seen in vitamin $\mathrm{D}$ deficiency between men and women. Our study is in agreement with study done by Wei, et al. ${ }^{19}$ A study conducted in $2007-2010$ by NHANES recorded no major gender gaps between adults in the United States, ${ }^{20}$ while another study in 1998-2004 also done by NHANES found that men had a higher 25-OHD level than women. ${ }^{21}$ In Middle East countries, many studies have demonstrated the incidence of vitamin D levels. For example, in Saudi Arabian population, 25-37\% of healthy Saudi men with low vitamin $\mathrm{D}$ have been reported although sunny days are abundant almost year around. ${ }^{21}$ This study is more comparable to our result as $35.23 \%$ of men in our population had a low 25(OH)D level. The fact that there was no significant difference between genders due to sun avoidance behaviour is limited by lifestyle and other choices as most females in our society spend more of their time at home rather than in other places. Additionally, wearing a Hijab, full body covered clothes and using sunscreen, and sunglasses makes it difficult to get enough vitamin D only from diet as well as gender differences may also be caused by differences in hormone levels leading to effect on this value. Therefore, long-term supplementation is possibly needed for patients with this nutritional deficiency and they should change their lifestyle behaviour.

Our findings reported that there was significant difference in 25(OHD) levels between the Dohuk and Zakho population. People are more likely to live in cities due to the rapid urbanization phase and higher socioeconomic status, and higher population density areas have contributed to reduced exposure to natural sunlight. Moreover, air contamination in urban areas may influence too by acting as a boundary to UV light but this suggested pathway has not elucidated clearly. ${ }^{22}$ The factor of race, ethnicity, country of residence and skin colour could explain the differences of 25(OHD) levels among the population. In our society, these factors can be ignored as most of our population are Kurdish sharing the same culture and tradition. On the other hand, many studies have shown racial differences could contribute to different 25(OHD) concentrations. Population from the UK, Australia, Canada, and the Middle East has lower 25(OHD) levels compared to white population. ${ }^{23,24}$ Moreover, African American have lower levels of vitamin D than their white population due to skin pigmentation that decreases vitamin D production. ${ }^{25}$

Furthermore, in this study, we found that there was also a significant difference between different age groups related to serum 25(OHD) levels $(P<0.001)$. Maximum incidence of vitamin $\mathrm{D}$ deficiency was observed in younger age group between $20-40$ years old (46.23\%) followed by aged $40-60$ years $(36.44 \%)$ while in older people the incidence of vitamin D deficiency was lower than the other groups (30\%) vitamin $\mathrm{D}$ levels decline with age, ${ }^{26}$ these studies found that production of this vitamin in the skin, calcium absorption of circulated $1,25(\mathrm{OH}) 2 \mathrm{D}$, and renal production of $1,25(\mathrm{OH}) 2 \mathrm{D}$ decrease after the sixth decade of life. ${ }^{27}$ It could be due to supplementation of vitamin $\mathrm{D}$ among elderly people, especially female, who are getting used to taking vitamin D supplementation or they depend on regular and adequate amount of food rich in vitamin $\mathrm{D}$ and spend more time in the sun. In addition to clothing habit/lifestyle, modification among younger people partly could explain the results. Younger people prefer living in apartments and have less outdoor physical activity whereas older people prefer living in houses and have had more outdoor physical activity when they were younger.

We concluded that the low incidence of vitamin $\mathrm{D}$ in older adults might be subject to vitamin $\mathrm{D}$ supplementation in this group or have more dietary supplements or maybe have more varied sources of vitamin D nutrients. Younger adults 
and females had a higher prevalence of vitamin D deficiency compared to older people and male. Our study is in agreement with the study which is done by Maldonado, et al. ${ }^{28}$ who demonstrated that the level of vitamin $\mathrm{D}$ in older adults is lower than other age groups.

\section{Competing Interests}

The authors declare that there are no competing interests.

\section{Funding/Support}

No funding or support.

\section{Acknowledgments}

We would like to thank the staff of Azadi hospital in Duhok and Zakho general hospital, Kurdistan region, Iraq for their assistance in data collection and laboratory analysis.

\section{References}

1. Basit S. Vitamin D in health and disease: a literature review. British journal of biomedical science. 2013;70(4):161-72.

2. Pedersen JI. Vitamin D requirement and setting recommendation levels current Nordic view. Nutr Rev. 2008;66(10 Suppl 2):S165-S9.

3. Guessous I, Bochud M, Bonny O, Burnier M. Calcium, vitamin D and cardiovascular disease. Kidney \& blood pressure research. 2011;34(6): 404-17.

4. Gagnon C, Lu ZX, Magliano DJ, Dunstan DW, Shaw JE, Zimmet PZ, et al. Serum 25-hydroxyvitamin D, calcium intake, and risk of type 2 diabetes after 5 years: results from a national, population-based prospective study (the Australian Diabetes, Obesity and Lifestyle study). Diabetes care. 2011;34(5):1133-8

5. Cutolo M, Plebani M, Shoenfeld Y, Adorini L, Tincani A. Vitamin D endocrine system and the immune response in rheumatic diseases. Vitamins \& Hormones. 86: Elsevier; 2011. p. 327-51.

6. Giordano N, Goracci A, Fagiolini A. Depression and vitamin D deficiency: causality, assessment, and clinical practice implications. Neuropsychiatry. 2017;7(5):606-14.

7. Brewer L, Williams D, Moore A. Current and future treatment options in osteoporosis. European journal of clinical pharmacology. 2011;67(4): 321-31.

8. Lagishetty V, Liu NQ, Hewison M. Vitamin D metabolism and innate immunity. Molecular and cellular endocrinology. 2011;347(1-2):97-105.

9. Christesen HT, Falkenberg T, Lamont RF, Jørgensen JS. The impact of vitamin D on pregnancy: a systematic review. Acta obstetricia et gynecologica Scandinavica. 2012;91(12):1357-67.

10. Ibrahim N, Shivan Y, Amer B, Djwar Ali K, Nawfal H. Study on Anticardiolipin Antibodies in Women With Recurrent Abortion in Duhok Province, Kurdistan Region, Iraq. Acta Medica Iranica. 2020;58(6).

11. A. Naqid I, H. Yousif S, R. Hussein N. Seroprevalence of Rubella and Herpes Simplex Virus in Women with Miscarriage and Stillbirth in Zakho City, Kurdistan Region, Iraq: A Cross- Sectional Study. Women's Health Bulletin. 2020;7(1):18-22.

12. Nagid IA, Yousif SH, Hussein NR. Serological Study of lgG and lgM Antibodies to Cytomegalovirus and Toxoplasma Infections in Pregnant Women in Zakho City, Kurdistan Region, Iraq. Women's Health Bulletin. 2019;6(4):8-12.

13. Vanga SR, Good M, Howard PA, Vacek JL. Role of vitamin D in cardiovascular health. The American journal of cardiology. 2010;106(6):798-805.

14. Bischoff-Ferrari HA, Dawson-Hughes B, Staehelin HB, Orav JE, Stuck $A$, Theiler R, et al. Fall prevention with supplemental and active forms

of vitamin D: a meta-analysis of randomised controlled trials. Bmj. 2009;339:b3692.

15. Joshi D, Center JR, Eisman JA. Vitamin D deficiency in adults. 2010

16. Sayed-Hassan R, Abazid N, Alourfi Z. Relationship between 25-hydroxyvitamin D concentrations, serum calcium, and parathyroid hormone in apparently healthy Syrian people. Archives of osteoporosis. 2014;9(1):176.

17. Badawi A, Arora P, Sadoun E, Al-Thani A-A, Thani MHA. Prevalence of vitamin $d$ insufficiency in qatar: a systematic review. Journal of public health research. 2012;1(3):229-35.

18. Palacios C, Gonzalez L. Is vitamin D deficiency a major global public health problem? The Journal of steroid biochemistry and molecular biology. 2014;144 Pt A:138-45.

19. Wei J, Zhu A, Ji JS. A comparison Study of Vitamin D Deficiency among Older Adults in china and the United States. Scientific Reports. 2019;9(1): $1-11$.

20. Jain R. Variability in the levels of vitamin D by age, gender, and race/ ethnicity: data from National Health and Nutrition Examination Survey 2007-2010. J Nutr Health Sci. 2016;3(2):203.

21. Sadat-Ali M, Al Elq AH, Al-Turki HA, Al-Mulhim FA, Al-Ali AK. Influence of vitamin D levels on bone mineral density and osteoporosis. Annals of Saudi medicine. 2011;31(6):602-8.

22. Agarwal K, Mughal M, Upadhyay P, Berry J, Mawer E, Puliyel J. The impact of atmospheric pollution on vitamin D status of infants and toddlers in Delhi, India. Archives of disease in childhood. 2002:87(2):111-3.

23. Vieth R, Cole D, Hawker G, Trang H, Rubin L. Wintertime vitamin D insufficiency is common in young Canadian women, and their vitamin D intake does not prevent it. European journal of clinical nutrition. 2001:55(12):1091-7.

24. Brock K, Wilkinson M, Cook R, Lee S, Bermingham M. Associations with Vitamin D deficiency in "at risk" Australians. J Steroid Biochem Mol Biol. 2004:89-90(1-5):581-8.

25. Harris SS. Vitamin D and african americans. The Journal of nutrition. 2006;136(4):1126-9.

26. Wacker M, Holick MF. Sunlight and Vitamin D: A global perspective for health. Dermato-endocrinology. 2013;5(1):51-108.

27. Gallagher JC. Vitamin D and aging. Endocrinology and Metabolism Clinics. 2013:42(2):319-32

28. Maldonado G, Paredes C, Guerrero R, Ríos C. Determination of Vitamin D Status in a Population of Ecuadorian Subjects. The Scientific World Journal. 2017;2017.

This work is licensed under a Creative Commons Attribution-NonCommercial 3.0 Unported License which allows users to read, copy, distribute and make derivative works for non-commercial purposes from the material, as long as the author of the original work is cited properly. 